\title{
Rendimento de forragem e valor nutritivo de gramíneas anuais de estação fria submetidas a sombreamento por Pinus elliottii e ao sol pleno ${ }^{1}$
}

\author{
Raquel Santiago Barro ${ }^{2}$, João Carlos de Saibro ${ }^{3}$, Renato Borges de Medeiros ${ }^{3}$, Jamir Luis \\ Silva da Silva ${ }^{3}$, Alexandre Costa Varella ${ }^{4}$ \\ ${ }^{1}$ Entidades financiadoras: EMBRAPA (Projeto SEG02.031.05), Faculdade de Agronomia/Departamento de Plantas Forrageiras e Agrometeorologia/ \\ UFRGS. \\ 2 Programa de Pós Graduação em Zootecnia/Universidade Federal do Rio Grande do Sul - Bolsista CAPES. \\ ${ }^{3}$ Faculdade de Agronomia/Departamento de Plantas Forrageiras e Agrometeorologia/UFRGS. \\ ${ }^{4}$ EMBRAPA Pecuária Sul, Bagé, RS.
}

\begin{abstract}
RESUMO - Avaliou-se o efeito do sombreamento provocado por duas densidades arbóreas em uma floresta de Pinus elliottii Engelm. com 10 anos de idade sobre o rendimento e o valor nutritivo da forragem de três gramíneas de ciclo hibernal. Como tratamentos, avaliou-se a combinação de dois fatores $(3 \times 3)$ em um delineamento experimental de parcelas subdivididas com três repetições, no qual as parcelas foram as condições luminosas (proporcionadas por duas densidades arbóreas: 555 e 333 árvores/ha e luz solar plena) e as subparcelas as espécies forrageiras azevém-anual (Lolium multiflorum Lam.); aveia-preta (Avena strigosa Schreb.); e aveia-branca (A. sativa L.) cv. Fapa 2. A semeadura foi realizada entre 25/7/2005 e 5/8/2005 e entre 26 e 27/4/2006. O rendimento de matéria seca foi estimado em avaliações durante o estádio vegetativo (aos 104 dias após a semeadura em 2006) e em pleno florescimento (aos 132 e 170 dias, em 2005 e 2006, respectivamente). O valor nutritivo da forragem foi avaliado considerando os teores médios de proteína bruta (PB) e a digestibilidade in vitro da matéria orgânica (DIVMO). O sombreamento moderado reduziu em $57 \%$ o rendimento médio de forragem dos três genótipos avaliados, mas aumentou em 2,3\% o teor de proteína bruta (PB) e em 5,5\% a digestibilidade in vitro (DIVMO) quando as plantas estavam em florescimento pleno. Entre as espécies forrageiras avaliadas, a aveia-branca e a aveia-preta apresentam maior potencial para utilização em sistemas silvipastoris na Região Sul.
\end{abstract}

Palavras-chave: Avena sativa, Avena strigosa, densidade arbórea, Lolium multiflorum, sistemas silvipastoris, sombreamento moderado

\section{Forage yield and nutritive value of cool-season annual forage grasses shaded by Pinus elliottii trees and at full-sun}

\begin{abstract}
It was evaluated the shading effect induced by two tree densities of a ten-year-old slash pine (Pinus elliottii Engelm.) forest, and at full sun, on forage dry matter yield and nutritive value of three cool-season annual grasses. Treatments were a combination of two main factors: a) three light conditions induced by two tree densities (333 e 555 stems/ha) and at full sun; b) three cool-season annual forage grasses: Italian ryegrass (Lolium multiflorum Lam.), common oat (Avena sativa L.) cv. Fapa-2, and black-oat (Avena strigosa Schreb.). A split-plot experimental design, with three replications, was used. The main plots were the light conditions affected by tree density and the subplots were the different forage species. Sowing dates were from July 25 to August 5, 2005 and April 26 and 27, 2006. In order to determine forage DM yield, plants were hand-clipped at the vegetative stage (104 days after sowing, in 2006) and at full bloom (132 and 170 days, in 2005 e 2006, respectively). Forage nutritive value was accessed by determining crude protein (CP) concentration and in vitro organic matter digestibility (IVOMD). Results showed that when plants were at the full bloom stage and under moderate shading, forage DM yield was reduced by $57 \%$, forage $\mathrm{CP}$ content was increased by 2,3\%, and IVOMD was raised by 5,5\%, compared to plants at full sun. In terms of their potential utilization, common oat and black-oat show promise for regional silvopastoral systems in southern Brazil.
\end{abstract}

Key Words: Avena sativa, Avena strigosa, Lolium multiflorum, moderate shading, silvopastoral systems, tree density

\section{Introdução}

O estado do Rio Grande do Sul apresenta aproximadamente 364.770 hectares plantados com espécies florestais exóticas, dos quais 185.080 são ocupados com espécies do gênero Pinus sp. (ABRAF, 2006). Na região litoral norte do estado, a exploração de florestas de Pinus elliiotti Engelm. e Pinus taeda L., em conjunto com a pecuária de

Este artigo foi recebido em 19/4/2007 e aprovado em 7/5/2008.

Correspondências devem ser enviadas para raquel.barro@ufrgs.br. 
corte baseada na pastagem nativa, é atualmente a principal atividade do setor produtivo primário. Para promover integração sustentável destas duas atividades, o uso de sistemas silvipastoris (SSP) tem sido recomendado, tanto para as regiões tropicais (Garcia \& Couto, 1997) quanto para as subtropicais brasileiras (Silva, 1998; Lucas, 2004).

O sucesso produtivo dos SSP para produção forrageira depende basicamente da interação otimizada da densidade arbórea com o crescimento e a qualidade da pastagem no sub-bosque sombreado, em virtude das alterações provocadas pela redução da radiação fotossinteticamente ativa imposta pelas árvores, tanto em quantidade quanto em qualidade da luz. De acordo com Lin et al. (1999), todas as plantas respondem fisiológica e morfologicamente à atenuação luminosa e essa resposta varia conforme o grau de tolerância da planta à sombra, uma expressão do seu genótipo. Em geral, o rendimento de matéria seca das gramíneas forrageiras de estação fria reduz tanto sob sombra artificial (Lin et al., 1999; Masuda, 1977) quanto sob sombra natural (Sartor et al., 2006; Silva, 1998). Entretanto, os efeitos do sombreamento sobre o valor nutritivo da forragem ainda não foram bem esclarecidos (Wilson \& Wong, 1982; Jackson \& Ash, 1998). Atualmente, nas condições edafoclimáticas do Rio Grande do Sul, não são conhecidas as relações entre o rendimento e o teor de proteína bruta e a digestibilidade in vitro da matéria orgânica de azevémanual (Lolium multiflorum Lam.), aveia-branca (Avena sativa L.) e aveia-preta (Avena strigosa Schreb.) sob níveis de sombreamento ocasionados por $P$. elliottii.

Objetivou-se com este trabalho avaliar o rendimento de matéria seca e o valor nutritivo da forragem de três genótipos de gramíneas forrageiras exóticas anuais de estação fria, muito utilizados em sistemas de produção animal no estado, sob sombreamento provocado por duas densidades arbóreas de Pinus elliottii, em comparação a sol pleno, em busca de novas informações para apoiar o desenvolvimento de sistemas silvipastoris como alternativa sustentável de uso da terra no Litoral Norte do Rio Grande do Sul.

\section{Material e Métodos}

O trabalho foi realizado em dois sítios experimentais: uma área de bosque de Pinus elliottii e outra sem presença de árvores (fora do bosque), áreas pertencentes à Empresa Florestal Flosul Ltda., localizada no munícipio de Capivari do Sul. O solo é classificado como Neossolo quartzarênico hidromórfico típico, Unidade de Mapeamento Curumim (Streck et al., 1999), extremamente arenoso e de baixíssima fertilidade natural ( $\mathrm{pH} 4,5$; teor de matéria orgânica de 0,5 a
0,8\%; fósforo de 2,1 a $19,0 \mathrm{mg} / \mathrm{dm}^{3}$; potássio de 14 a $55 \mathrm{mg} / \mathrm{dm}^{3}$; CTC de 2,4 a 4,1 $\mathrm{cmol}_{\mathrm{c}} / \mathrm{dm}^{3}$; cálcio de 0,1 a $0,2 \mathrm{cmol}_{\mathrm{c}} / \mathrm{dm}^{3}$; e magnésio de $\left.0,1 \mathrm{cmol}_{\mathrm{c}} / \mathrm{dm}^{3}\right)$.

O clima da região é do tipo Cfa, subtropical úmido, com precipitação pluvial média anual de $1.247 \mathrm{~mm}$, média de 102,9 dias de chuva/ano e temperatura média anual de $19,7^{\circ} \mathrm{C}$. A evapotranspiração potencial média anual é de $946 \mathrm{~mm}$, com deficiência hídrica de $25 \mathrm{~mm}$ nos meses de dezembro e janeiro e excedente de $326 \mathrm{~mm}$ nos meses de junho a outubro (Maluf, 1978).

O bosque de Pinus elliottii foi estabelecido em 1995 em densidade de 1.666 árvores/ha, em arranjo de linhas simples espaçadas a $3 \mathrm{~m}$, com $2 \mathrm{~m}$ entre as árvores $(3 \times 2 \mathrm{~m})$. Em fevereiro de 2005, foi realizado o desbaste visando obter duas densidades arbóreas (555 e 333 árvores/ha), em arranjos de $9 \times 2 \mathrm{~m}$ e $15 \times 2 \mathrm{~m}$, obtidos por meio do corte sistemático de duas e três linhas de árvores contíguas, respectivamente.

Em julho de 2005, foram realizadas calagem e adubação por meio da aplicação de calcário dolomítico em quantidades equivalentes a $3 \mathrm{t} / \mathrm{ha}$ e a $600 \mathrm{~kg} / \mathrm{ha}$ de adubo da fórmula NPK 6-24-18, com base na recomendação da análise de solo. A incorporação dos insumos ao solo foi realizada utilizando-se motocultivador a $10 \mathrm{~cm}$ de profundidade.

As espécies forrageiras foram semeadas em parcelas alocadas aleatoriamente nas entrelinhas das árvores, em um total de 27 unidades experimentais. A área das parcelas na densidade de 555 árvores/ha foi de $18 \mathrm{~m}^{2}(9 \times 2 \mathrm{~m}) \mathrm{e}$, na densidade de 333 árvores/ha, de $30 \mathrm{~m}^{2}(15 \times 2 \mathrm{~m})$. A área fora do bosque (pleno sol) foi composta por parcelas de $8 \mathrm{~m}^{2}(4 \times 2 \mathrm{~m})$.

Foram realizadas duas semeaduras correspondentes aos dois anos consecutivos (2005 e 2006) de cultivo das gramíneas: azevém-anual (Lolium multiflorum Lam), aveiapreta (Avena strigosa Schreb.), aveia-branca (A. sativa L.) cv. Fapa-2; no primeiro ano, a semeadura foi realizada entre os dias 25 de julho e 5 de agosto de 2005 utilizando-se, respectivamente, quantidades equivalentes a 40, 60 e $80 \mathrm{~kg} / \mathrm{ha}$ de sementes. Em 7 de abril 2006, foram realizadas a calagem e a adubação de manutenção com calcário e adubo da fórmula NPK 05-20-20 em quantidades equivalentes a 600 e $200 \mathrm{~kg} / \mathrm{ha}$. A semeadura foi realizada em 26 e 27 de abril utilizando-se as mesmas densidades de semeadura. A adubação nitrogenada de cobertura foi realizada com uréia cloretada (20-00-20 NPK), em quantidades de nitrogênio e $\mathrm{K}_{2} \mathrm{O}$ equivalentes a $36 \mathrm{~kg} / \mathrm{ha}+36 \mathrm{~kg} / \mathrm{ha}, 41$ dias após a semeadura e mais $45 \mathrm{~kg} / \mathrm{ha}$ de nitrogênio aos 108 dias após a semeadura, logo após o primeiro corte, usando uréia comum, em um total de $81 \mathrm{~kg} / \mathrm{ha}$ de nitrogênio. 
A radiação fotossinteticamente ativa (RFA) foi medida com um ceptômetro Decagon, modelo AccuPAR, dentro e fora do bosque. As medidas foram tomadas fora do bosque (para a RFA incidente) e no sub-bosque (para a fração da RFA transmitida ao estrato herbáceo). As leituras da radiação (Tabela 1), realizadas nos dias 27 de abril, 16 de maio e 23 de agosto de 2006, foram tomadas entre as $11 \mathrm{~h} 30$ e 13h30, hora local, por meio de transecções, de modo que a cada 2 m era feita uma leitura, em três retas, correspondendo a posições distintas da entrelinha de árvores (no centro da entrelinha e a $2 \mathrm{~m}$ das linhas de árvores). Ao final de cada repetição dentro do bosque, foi realizada uma leitura correlativa sob sol pleno.

Neste trabalho, a condição luminosa na densidade de 333 árvores/ha será designada como sombra fraca e, na densidade de 555 árvores/ha, como sombra moderada, conforme caracterizado pelos dados médios de radiação (Tabela 1). Como tratamento, avaliou-se a combinação dos níveis dos dois fatores (condições luminosas e gramíneas forrageiras), estabelecidos segundo um fatorial $3 \times 3$, com três repetições, em um total de 27 unidades experimentais. O delineamento experimental foi em parcelas subdivididas, no qual as parcelas principais foram formadas pelas três condições luminosas e as subparcelas, pelas três espécies forrageiras, arranjadas em três blocos completos casualizados e avaliadas em dois ciclos produtivos, correspondentes a dois anos consecutivos (2005 e 2006).

$\mathrm{O}$ efeito do sombreamento foi avaliado por meio de cortes visando estimar o rendimento de forragem e seu valor nutritivo. As amostras foram coletadas em quadros com áreas de $625 \mathrm{~cm}^{2}$, seis dentro do bosque e duas fora do bosque, por unidade experimental. Os cortes foram realizados manualmente com foice, a $10 \mathrm{~cm}$ acima do solo. No primeiro ano, o corte foi realizado no dia $1^{\circ}$ de novembro, 132 dias após a semeadura. No segundo ano, foram realizados dois cortes: o primeiro no dia 8 de agosto, com as plantas em estádio vegetativo, 104 dias após a semeadura; e o segundo no dia 13 de outubro de 2006, com as plantas em florescimento, 170 dias após a semeadura. As amostras de forragem fresca foram acondicionadas em sacos plásticos, pesadas, secas a $65^{\circ} \mathrm{C}$, até peso seco constante, e moídas.
Para estimativa do valor nutritivo, foram avaliados o teor de proteína bruta $(\mathrm{PB})$, pela relação nitrogênio total $\times 6,25$, conforme AOAC (1975), e a digestibilidade in vitro da matéria orgânica (DIVMO), determinada conforme descrito por Close \& Menke (1986).

Os resultados foram submetidos à análise da variância (ANOVA) e o efeito médio do sombreamento foi comparado pelo teste Tukey a $5 \%$ de probabilidade.

\section{Resultados e Discussão}

O rendimento médio de matéria seca da forragem das gramíneas em dois anos e em cada ano reduziu $(\mathrm{P} \leq 0,05)$ com o aumento do sombreamento; os rendimentos médios de forragem sob sombreamento moderado e sob sombreamento fraco corresponderam, respectivamente, a 43 e $66 \%$ do rendimento obtido em condição de sol pleno (Tabela 2). As reduções médias do rendimento de forragem obtidas nos dois níveis de sombreamento foram mais pronunciadas que as relatadas por Sartor et al. (2006), em Abelardo Luz, Santa Catarina. Esses autores avaliaram o desempenho produtivo das mesmas espécies sob densidades arbóreas de Pinus elliottii semelhantes (222 e 370 árvores/ha) e relataram reduções de 37 e $56 \%$ no rendimento de forragem, na menor e na maior densidade, em comparação a sol pleno. O rendimento de MS foi maior $(\mathrm{P}<0,05)$ em 2006, nas três condições luminosas, em virtude do maior rendimento a sol pleno, no entanto, não diferiu $(\mathrm{P}>0,05)$ entre os níveis de sombreamento (Tabela 2).

Nas três condições luminosas, a aveia-branca e aveiapreta não diferiram significativamente $(\mathrm{P}>0,05)$ entre si e apresentaram rendimento de forragem maior que o obtido com azevém-anual (Tabela 3 ). O azevém-anual foi a espécie que sofreu os maiores decréscimos produtivos com o aumento da restrição luminosa e apresentou rendimentos relativos de apenas 45,8 e $37,5 \%$, respectivamente, para sombra fraca e sombra moderada em comparação ao sol pleno. As aveias apresentaram rendimentos relativos médios bem superiores, em torno de 75,0 e 46,0\% nas duas condições de sombra (Tabela 3). A tendência de redução progressiva do rendimento de forragem provocada pelo aumento da

Tabela 1 - Radiação fotossinteticamente ativa transmitida (RFAt) e percentual de transmissão em duas densidades arbóreas

\begin{tabular}{|c|c|c|c|c|c|c|c|c|}
\hline \multirow[t]{2}{*}{ Condição luminosa } & \multicolumn{2}{|c|}{$27 / 4 / 2006$} & \multicolumn{2}{|c|}{$16 / 5 / 2006$} & \multicolumn{2}{|c|}{$23 / 8 / 2006$} & \multicolumn{2}{|c|}{ Média } \\
\hline & RFAt $^{1}$ & $\%$ & RFAt & $\%$ & RFAt & $\%$ & RFAt & $\%$ \\
\hline Sol pleno & 1.185 & 100 & 935 & 100 & 1.134 & 100 & 1.085 & 100 \\
\hline Sombra fraca ${ }^{2}$ & 892 & 75 & 752 & 80 & 827 & 73 & 823 & 76 \\
\hline Sombra moderada ${ }^{3}$ & 517 & 44 & 379 & 41 & 536 & 47 & 477 & 44 \\
\hline
\end{tabular}

${ }^{1}$ RFAt em $\mathrm{mmol} / \mathrm{m}^{2} / \mathrm{s} ;{ }^{2}$ Sombra fraca $=333$ árvores $/ \mathrm{ha} ;{ }^{3}$ Sombra moderada $=555$ árvores $/$ ha. 
Tabela 2 - Rendimento total de matéria seca de azevém-anual, aveia-branca e aveia-preta sob três condições luminosas em 2005 (um corte) e 2006 (dois cortes)

\begin{tabular}{lccc}
\hline Condição luminosa & 2005 & 2006 & Média \\
\cline { 2 - 3 } & & $\mathrm{kg} / \mathrm{ha}$ & \multicolumn{2}{c}{ Rendimento relativo } \\
\hline Sol pleno & $3.116 \mathrm{Ab}^{1}$ & $4.148 \mathrm{Aa}$ & $3.632 \mathrm{~A}$ \\
Sombra fraca & $2.411 \mathrm{Ba}$ & $2.384 \mathrm{Ba}$ & $2.398 \mathrm{~B}$ \\
Sombra moderada $^{3}$ & $1.515 \mathrm{Ca}$ & $1.622 \mathrm{Ca}$ & $60 \%$ \\
Média & $2.347 \mathrm{~b}$ & $2.718 \mathrm{a}$ & $4.568 \mathrm{C}$ \\
\hline
\end{tabular}

Médias das três espécies e três repetições. Capivari do Sul, Rio Grande do Sul.

${ }^{1}$ Médias seguidas por letras minúsculas diferentes nas linhas ou por letras maiúsculas diferentes nas colunas, diferem pelo teste Tukey a $5 \%$ de significância.

2 Sombra fraca $=333$ árvores/ha.

${ }^{3}$ Sombra moderada $=555$ árvores $/$ ha.

Tabela 3 - Rendimento total de matéria seca de azevém-anual, aveia-branca e aveia preta em três condições luminosas

\begin{tabular}{|c|c|c|c|c|}
\hline \multirow[t]{3}{*}{ Condição luminosa } & \multicolumn{3}{|c|}{ Espécie } & \multirow[t]{3}{*}{ Média } \\
\hline & Azevém-anual & Aveia-branca & Aveia-preta & \\
\hline & \multicolumn{3}{|c|}{ (kg/ha) } & \\
\hline Sol pleno & $3.303(100 \%)^{2}$ & $3.717(100 \%)$ & $3.877(100 \%)$ & $3.632 \mathrm{~A}^{1}$ \\
\hline Sombra fraca $^{3}$ & $1.513(45,8 \%)$ & $2.773(74,6 \%)$ & $2.907(75,0 \%)$ & $2.398 \mathrm{~B}$ \\
\hline Sombra moderada ${ }^{4}$ & $1.238(37,5 \%)$ & $1.841(49,5 \%)$ & $1.627(42,0 \%)$ & $1.568 \mathrm{C}$ \\
\hline Média & $2.018 \mathrm{~b}^{1}$ & $2.777 \mathrm{a}$ & $2.804 \mathrm{a}$ & 2.533 \\
\hline
\end{tabular}

Médias de dois anos e três repetições. Capivari do Sul, Rio Grande do Sul.

1 Médias seguidas de letras minúsculas diferentes nas linhas, ou por letras maiúsculas diferentes nas colunas, diferem pelo teste Tukey a $5 \%$ de significância.

2 Números entre parênteses: rendimento relativo.

3 Sombra fraca $=333$ árvores/ha.

4 Sombra moderada $=555$ árvores $/$ ha.

restrição luminosa evidenciada neste trabalho confirma resultados obtidos em avaliações destas gramíneas conduzidas em diversas condições agroecológicas, tanto no sul do Brasil (Saibro, 1992) quanto no exterior (Watson et al., 1984; Masuda, 1977), comprovando a existência de relação negativa entre o aumento da densidade arbórea e a produção de forragem do sub-bosque.

$\mathrm{Na}$ análise da variância, a digestibilidade in vitro da matéria orgânica (DIVMO) da forragem colhida no ano de 2005 diferiu significativamente entre as condições luminosas. $\mathrm{O}$ teste de médias indicou diferença $(\mathrm{P}<0,05)$ entre as condições de sombra fraca e sombra moderada, que não diferiram $(\mathrm{P}>0,05)$ da luminosidade plena, todavia os maiores valores de DIVMO foram obtidos na condição de maior sombreamento. No ano de 2005, não houve influência ( $\mathrm{P}>0,05)$ das condições luminosas sobre os teores de proteína bruta das forrageiras avaliadas (Tabela 4).

Em 2005, o azevém-anual apresentou os maiores valores (P 0,05) de DIVMO e PB, seguido pela aveia-branca e pela aveia-preta, independentemente da condição luminosa (Tabela 4). Ressalta-se, porém, que as aveias apresentaram DIVMO e teores de PB satisfatórios e que o teor de PB foi superior ao mínimo de $7 \%$ para o bom desempenho de novilhos em pastejo.

Pela análise de variância, a DIVMO não diferiu $(\mathrm{P}>0,05)$ entre as condições luminosas, as gramíneas forrageiras e os dois cortes no ano de 2006. Entretanto, a tendência de maiores teores de DIVMO observada sob sombra em 2005 (Tabela 4) repetiu-se em 2006 (Tabela 5). Do mesmo modo, o teor de $\mathrm{PB}$ aumentou nas condições de sombra e não diferiu entre o teor de PB sob luz solar plena e sombra moderada $(\mathrm{P}>0,05)$ nem entre as duas condições de sombra (Tabela 5).

No ano de 2006, diferente do observado em 2005, a aveia-branca apresentou os maiores valores $(\mathrm{P}<0,05)$ de DIVMO em todas as condições luminosas avaliadas (Tabela 5). O azevém-anual apresentou menores teores de $\mathrm{PB}(\mathrm{P}<0,05)$ em comparação à aveia-branca e à aveiapreta (Tabela 5).

Em 2005, os teores médios de PB não diferiram entre as três condições luminosas (Tabela 4), enquanto, em 2006, os maiores teores de PB foram observados nas condições de sombra (Tabela 5). De modo geral, estudos comprovam aumentos relativos nos teores de proteína bruta da forragem sob sombreamento em comparação ao sol pleno. Pesquisadores (Kephart \& Buxton, 1993; Jackson \& Ash, 1998; Lin et al., 2001; Varella et al., 2001; Buergler et al., 2006) relatam que, em diversas gramíneas forrageiras de ciclo hibernal, os teores de PB da forragem aumentam com a restrição luminosa.

Em geral, os autores atribuem os maiores teores de PB em plantas cultivadas sob sombreamentoà maior mineralização 
Tabela 4 - Digestibilidade in vitro da matéria orgânica (DIVMO) e teor de proteína bruta (PB) da forragem de azevém-anual, aveia-branca e aveia-preta aos 94 dias após a semeadura (estádio de florescimento), cultivadas sob três condições de luminosidade

\begin{tabular}{|c|c|c|c|c|}
\hline \multirow[t]{2}{*}{ Condição luminosa } & \multicolumn{3}{|c|}{ Espécie } & \multirow[t]{2}{*}{ Média } \\
\hline & \multicolumn{3}{|c|}{ DIVMO (\%) } & \\
\hline Sol pleno & 69,0 & 65,0 & 57,0 & $63,7 \mathrm{AB}^{1}$ \\
\hline Sombra fraca ${ }^{2}$ & 69,0 & 61,7 & 55,0 & $61,9 \mathrm{~B}$ \\
\hline Sombra moderada ${ }^{3}$ & 73,0 & 69,3 & 59,0 & $67,1 \mathrm{~A}$ \\
\hline Sol pleno & 14,0 & 12,0 & 11,3 & $12,4 \mathrm{~A}$ \\
\hline Sombra fraca ${ }^{2}$ & 13,3 & 11,7 & 11,0 & $12,0 \mathrm{~A}$ \\
\hline Sombra moderada ${ }^{3}$ & 15,7 & 10,3 & 9,0 & $11,7 \mathrm{~A}$ \\
\hline Média & $14,3 \mathrm{a}$ & $11,3 b$ & $10,4 \mathrm{c}$ & 12,0 \\
\hline
\end{tabular}

Médias de três repetições. Capivari do Sul, Rio Grande do Sul, 1o de novembro de 2005.

${ }^{1}$ Médias seguidas por letras minúsculas diferentes nas linhas, ou por letras maiúsculas diferentes nas colunas, em cada parâmetro do valor nutritivo, diferem pelo teste Tukey a $5 \%$ de significância.

2 Sombra fraca $=333$ árvores/ha.

3 Sombra moderada $=555$ árvores $/$ ha.

Tabela 5 - Digestibilidade in vitro da matéria orgânica (DIVMO) e teor de proteína bruta (PB) da forragem de azevém-anual, aveia-branca e aveia-preta cultivadas em 2006 sob três condições de luminosidade

\begin{tabular}{|c|c|c|c|c|}
\hline \multirow[t]{3}{*}{ Condição luminosa } & \multicolumn{3}{|c|}{ Espécie } & \multirow[t]{3}{*}{ Média } \\
\hline & Azevém-anual & Aveia-branca & Aveia-preta & \\
\hline & \multicolumn{3}{|c|}{ DIVMO (\%) } & \\
\hline Sol pleno & 66,8 & 70,1 & 63,9 & $66,9 \mathrm{~A}^{1}$ \\
\hline Sombra fraca ${ }^{2}$ & 65,5 & 71,1 & 64,9 & $67,2 \mathrm{~A}$ \\
\hline Sombra moderada ${ }^{3}$ & 64,6 & 71,9 & 64,9 & $67,2 \mathrm{~A}$ \\
\hline \multirow[t]{2}{*}{ Média } & $65,6 b^{1}$ & $71,1 \mathrm{a}$ & $64,6 b$ & 67,1 \\
\hline & \multicolumn{3}{|c|}{$\mathrm{PB}(\%)$} & \\
\hline Sol pleno & 8,4 & 9,4 & 8,9 & $8,9 \mathrm{~B}$ \\
\hline Sombra fraca ${ }^{2}$ & 9,5 & 10,3 & 9,8 & $9,9 \mathrm{~A}$ \\
\hline Sombra moderada ${ }^{3}$ & 9,1 & 9,5 & 10,2 & $9,6 \mathrm{AB}$ \\
\hline Média & $9,0 \mathrm{a}$ & $9,7 \mathrm{a}$ & $9,6 \mathrm{a}$ & 9,5 \\
\hline
\end{tabular}

Médias de duas datas de corte (8/8/2006 - estádio vegetativo e 13/10/2006 - pleno florescimento) e três repetições. Capivari do Sul, Rio Grande do Sul.

${ }_{1}^{1}$ Médias seguidas por letras minúsculas diferentes nas linhas, ou por letras maiúsculas diferentes nas colunas, em cada parâmetro do valor nutritivo, diferem

pelo teste Tukey a $5 \%$ de significância.

2 Sombra fraca $=333$ árvores $/$ ha; ${ }^{3}$ Sombra moderada $=555$ árvores $/$ ha

da matéria orgânica do solo sob sombreamento ou ao atraso no desenvolvimento ontogenético de plantas mantidas em sombreamento em relação àquelas cultivadas sem restrição luminosa (Tiedmann et al., 1971; Castro et al., 1997; Addison \& Congdon, 2001). Entretanto, esse atraso no desenvolvimento é passível de causar confundimento com os reais efeitos do sombreamento, uma vez que, com o avanço da idade fisiológica, são alterados os conteúdos de carboidratos não-fibrosos (CNF) e de nutrientes e os teores de proteína, sílica, lignina e fibras, que determinam o valor nutritivo da forragem (Masuda, 1977).

Independentemente das condições luminosas, os valores de DIVMO e o teor de PB foram mais altos nas gramíneas em estádio vegetativo em comparação àquelas em florescimento. Considerando que, em ambos os cortes, as plantas estavam em florescimento pleno (Tabelas 4 e 6), é possível que o sombreamento moderado tenha afetado positivamente o valor nutritivo das gramíneas, uma vez que maiores $(\mathrm{P} \leq 0,05)$ valores de DIVMO foram obtidos nesta condição.

Na literatura constam desde dados coincidentes até resultados bastante discrepantes, ou mesmo contraditórios, sobre a digestibilidade de plantas em sombreamento. Alguns pesquisadores têm associado a menor qualidade de forragem em gramíneas sombreadas à menor digestibilidade in vitro, decorrente do aumento do conteúdo de lignina (Belsky, 1992; Lin et al., 2001), da redução dos teores de carboidratos não-fibrosos (CNF) ou do aumento 
do conteúdo de paredes celulares (CPC) nos tecidos das plantas (Belski, 1992).

Kepharth \& Buxton (1993) encontraram relação linear negativa $(\mathrm{P}<0,05)$ da DIVMS de faláris (Phalaris arundinacea L.) cv. Vantage, festuca-alta (Festuca arundinacea Schreb.) cv. Kentucky-31, Panicum virgatum L. cv. Cave-in-Rock e Panicum clandestinum L. cv. Tioga quando os níveis de transmissão da luz solar variaram de $37 \%$ para 70 e $100 \%$. Esses autores esclareceram que foram encontrados aumentos de aproximadamente cinco unidades percentuais na média dos materiais forrageiros avaliados, sugerindo que a DIVMS melhorou com a restrição luminosa, pois houve redução de $4 \%$ no teor de lignina e de $3 \%$ no teor de parede celular.

A maior digestibilidade observada na condição de sombra moderada nas plantas em florescimento pleno (Tabela 6) não pode ser explicada apenas como um efeito isolado da redução luminosa, pois pode estar associada às menores temperaturas no sub-bosque e à maior densidade arbórea. Conforme demonstraram Masuda (1977) e Ford et al. (1979) ao examinarem os efeitos da temperatura sobre a digestibilidade in vitro de forrageiras de estação fria, o valor nutritivo melhora em temperaturas amenas, principalmente em virtude da redução no teor de FDA (ou da lignina). Assim, neste trabalho conduzido sob a sombra de árvores de Pinus elliottii, a maior DIVMO na condição de sombra

Tabela 6 - Digestibilidade in vitro da matéria orgânica (DIVMO) e teor de proteína bruta (PB) da forragem de azevémanual, aveia-branca e aveia-preta, cultivadas em 2006 sob três condições luminosas, em duas datas de corte (8/8/2006 - estádio vegetativo e 13/10/2006 - florescimento pleno)

\begin{tabular}{|c|c|c|c|}
\hline \multirow[t]{3}{*}{ Condição luminosa } & \multicolumn{2}{|c|}{ Data do corte } & \multirow[t]{3}{*}{ Média } \\
\hline & $8 / 8$ & $13 / 10$ & \\
\hline & \multicolumn{2}{|c|}{ DIVMO (\%) } & \\
\hline Plena & $77,1 \mathrm{Aa}^{1}$ & $56,8 \mathrm{Bb}$ & $66,9 \mathrm{~A}$ \\
\hline Sombra fraca ${ }^{2}$ & $74,2 \mathrm{Ba}$ & $60,1 \mathrm{Ab}$ & $67,2 \mathrm{~A}$ \\
\hline Sombra moderada ${ }^{3}$ & $71,8 \mathrm{Ba}$ & $62,6 \mathrm{Ab}$ & $67,2 \mathrm{~A}$ \\
\hline \multirow[t]{2}{*}{ Média } & $74,3 \mathrm{a}$ & $59,8 b$ & 67,1 \\
\hline & \multicolumn{2}{|c|}{ PB (\%) } & \\
\hline Plena & $11,2 \mathrm{Ba}$ & $6,6 \mathrm{Bb}$ & $8,9 \mathrm{~B}$ \\
\hline Sombra fraca ${ }^{2}$ & $11,8 \mathrm{Aa}$ & $7,9 \mathrm{Ab}$ & $9,9 \mathrm{~A}$ \\
\hline Sombra moderada ${ }^{3}$ & $10,7 \mathrm{Ba}$ & $8,9 \mathrm{Ab}$ & $9,8 \mathrm{AB}$ \\
\hline Média & $11,3 \mathrm{a}$ & $7,8 \mathrm{~b}$ & 9,5 \\
\hline
\end{tabular}

Médias de três espécies e três repetições. Capivari do Sul, Rio Grande do Sul.

${ }^{1}$ Médias seguidas de letras minúsculas diferentes nas linhas, ou por letras maiúsculas diferentes nas colunas, em cada parâmetro do valor nutritivo, diferem pelo teste de Tukey a $5 \%$ de significância.

2 Sombra fraca $=333$ árvores $/$ ha.

3 Sombra moderada $=555$ árvores $/$ ha. moderada provavelmente esteve relacionada à redução da temperatura no sub-bosque com 555 árvores/ha em comparação ao ambiente sem a presença de árvores (sol pleno).

\section{Conclusões}

Em sistemas de produção silvipastoris, as forrageiras aveia-preta, aveia-branca e azevém-anual podem ser usadas para formar áreas de reservas alimentares in situ, para uso estratégico, pois a redução do valor nutritivo das plantas com a maturidade pode ser atenuada pelo sombreamento (condição de sub-bosque). Em comparação ao sol pleno, o sombreamento reduz o rendimento e aumenta, ou não afeta, o teor de proteína bruta $(\mathrm{PB})$ e a digestibilidade in vitro da matéria orgânica dessas forrageiras. $\mathrm{O}$ aumento da restrição luminosa, de sombra fraca para moderada, diminui o rendimento de matéria seca dos três genótipos. Independentemente das condições luminosas testadas, aveia-branca e aveia-preta apresentam rendimentos de forragem superiores aos do azevém-anual.

\section{Agradecimento}

À Coordenação de Aperfeiçoamento de Pessoal de Nível Superior (CAPES), pela bolsa de mestrado concedida ao primeiro autor. À empresa florestal FLOSUL Ltda., pela cessão da área de estudo. À EMBRAPA, pela concessão dos recursos para execução do experimento. Aos graduandos de Engenharia Agrícola da ULBRA Caio Pimenta e Daniel Brambilla, pelo apoio irrestrito nas atividades de campo e laboratório.

\section{Literatura Citada}

ASSOCIAÇÃO BRASILEIRA DE PRODUTORES DE FLORESTAS PLANTADAS - ABRAF. Anuário estatístico da ABRAF: ano base 2005. Brasília: 2006. 80p.

ADDISON, H.; CONGDON, R. Legumes for agroforestry systems. In: AUSTRALIAN AGRONOMY CONFERENCE, 10., 2001, Hobart. Proceedings... Hobart: Australian Society of Agronomy, 2001. (CD-ROM).

ASSOCIATION OF OFFICIAL ANNALYTICAL CHEMISTS AOAC. Official methods of analysis. 12.ed. Washington, D.C.: AOAC International, 1975. 1094p.

BELSKY, A.J. Effects of trees on nutritional quality of understorey gramineous forage in tropical savannas. Tropical Grasslands, v.26, n.1, p.12-20, 1992.

BUERGLER, A.L.; FIKE, J.H.; BURGER, J.A. et al. Forage nutritive value in an emulated silvopasture. Agronomy Journal, v.98, n.5, p. 1265-1273, 2006.

CASTRO, C.R.T.; CARVAlho, M.M.; GARCIA, R. Produção forrageira e alterações morfológicas em gramíneas cultivadas sob luminosidade reduzida. In: REUNIÃO ANUAL DA SOCIEDADE BRASILEIRA DE ZOOTECNIA, 34., 1997, Juiz de Fora. Anais... Juiz de Fora: Sociedade Brasileira de Zootecnia, Forragicultura, 1997. v.2, p.338-340. 
CLOSE, W.; MENKE, K.H. Selected topics in animal nutrition. Hokenheim, Germany: DSIE, 1986. 254p.

FORD, C.W.; MORRISON, I.M.; WILSON, J.R. Temperature effects on lignin, hemicellulose and cellulose in tropical and temperate grasses. Australian Journal of Agricultural Research, v.30, p.621-633, 1979.

GARCIA, R.; COUTO, L. Sistemas silvipastoris: tecnologia emergente de sustentabilidade. In: SIMPÓSIO INTERNACIONAL SOBRE PRODUÇÃO ANIMAL EM PASTEJO, 1997, Viçosa, MG. Anais... Viçosa, MG: UFV, 1997. p.447-471.

JACKSON, J.; ASH, A.J. Tree-grass relationships in open eucalypt woodlands of northeastern Australia: influence of trees on pasture productivity, forage quality and species distribution. Agroforestry Systems, v.40, p.159-176, 1998.

KEPHART, K.D.; BUXTON, D.R. Forage quality responses of $\mathrm{C}_{3}$ and $\mathrm{C}_{4}$ perennial grasses to shade. Crop Science, v.33, p.831$837,1993$.

LIN, C.H.; MCGRAW, R.L.; GEORGE, M.F. et al. Shade effects on forage crops with potential in temperate agroforestry practices. Agroforestry Systems, v.44, p.109-119, 1999.

LIN, C.H.; MCGRAW, R.L.; GEORGE, M.F. et al. Nutritive quality and morphological development under partial shade of some forage species with agroforestry potential. Agroforestry Systems, v.53, p.269-281, 2001.

LUCAS, N.M. Desempenho animal em sistema silvipastoril com acácia-negra (Acacia mearnsii De Wild.) e rendimento de matéria seca de cultivares dePanicum maximum Jacq. sob dois regimes de luz solar. Porto Alegre: Universidade Federal do Rio Grande do Sul, 2004. 127p. Tese (Doutorado em Zootecnia) - Universidade Federal do Rio Grande do Sul, 2004.

MALUF, J.R.T. Zoneamento agroclimático. In: MALUF, J.R.T. (Ed.) Plano integrado para o desenvolvimento do Litoral Norte do Rio Grande do Sul: adequação de uso do solo. Porto Alegre: EMMA, 1978. p.15-296.

MASUDA, Y. Comparisons of in vitro dry matter digestibility of forage oats grown under different temperatures and light intensities. Journal of the Faculty of Agriculture, Kyushu University, v.21, p.17-24, 1977.
SAIBRO, J.C. Programa de estímulo à integração de grupos e centros de pesquisa com o setor empresarial. Integração Silvipastoril de Eucalipto com Pastagens na Depressão Central no Rio Grande do Sul(Proc. № 91/1684-3). Porto Alegre: FAPERGS; RIOCELL S.A.; UFRGS, 1992. 101p. (Relatório Técnico Anual).

SARTOR, L.R.; MEZZALIRA, J.C.; SOARES, A.B. Produção de forrageiras hibernais em sistema silvipastoril. In: REUNIÃO DO GRUPO TÉCNICO EM FORRAGEIRAS DO CONE SUL ZONA CAMPOS, 11., 2006, Pelotas. Anais... Pelotas: 2006. (CD-ROM)

SILVA, J.L.S. Produtividade de componentes de um sistema silvipastoril constituído por Eucalyptus saligna Smith e pastagens cultivada e nativa no Rio Grande do Sul. Viçosa, MG: Universidade Federal de Viçosa, 1998. 178p. Tese (Doutorado em Zootecnia) - Universidade Federal de Viçosa, 1998.

STRECK, E.V.; KAMPF, N.; KLAMT, E. Atualização da classificação taxonômica das unidades de mapeamento do levantamento de reconhecimento dos solos do estado do Rio Grande do Sul. Informativo EMATER-RS, v.16, n.9, p.1-5, 1999.

TIEDEMANN, A.R.; KLEMMEDSON, J.O.; OGDEN. P.R. Response of four perennial southwestern grasses to shade. Journal of Range Management, v.24, p.442-447, 1971.

VARELLA, A.C.; PERI, P.L.; LUCAS, R.J. et al. Dry matter production and nutritive value of alfalfa (Medicago sativa L.) and orchardgrass (Dactylis glomerata L.) under different light regimes. In: INTERNATIONAL GRASSLAND CONGRESS, 19. 2001, São Pedro. Anais... São Pedro: Fundação de Estudos Agrários Luiz de Queiroz, 2001. p.658-659.

WATSON, V.H.; HAGEDORN, C.; KNIGHT, W.E. et al. Shade tolerance of grass and legume germplasm for use in the southern forest range. Journal of Range Management, v.37, n.3, p.229-232, 1984.

WILSON, J.R.; WONG, C.C. Effects of shade on some factors influencing nutritive quality of green panic and siratro pastures. Australian Journal of Agricultural Research, v.33, n.6, p.937-949, 1982. 